\title{
Is early flowering in myrmecochorous plants an adaptation for ant dispersal?
}

\author{
JAVIER GUITIÁN and JOSÉ L. GARRIDO \\ Departamento de Botánica, Facultad de Biología, Campus Sur, Universidad de Santiago de Compostela, 15708, Santiago de \\ Compostela, A Coruña, Spain
}

\begin{abstract}
To analyze the extent to which early flowering of specialized myrmecochorous plants (i.e. plants producing elaiosome-bearing seeds) may be the result of adaptation for ant dispersal, we investigated flowering and fruiting patterns of common herb and shrub-layer species in a beechwood forest at the western end of the Cantabrian Range (Spain). Over the same period, we estimated ant abundance, the availability of alternative foods for ants, and the rate of removal of seeds by ants. Our results indicate: (i) that the flowering peaks of most strict myrmecochores occurred approximately 4 weeks earlier than in nonmyrmecochores; (ii) that the fruiting peak of both groups of plants occurred around the same time, in early July; (iii) that the peak in ant abundance coincides with the seed availability peak, and precedes the peak in availability of alternative ant foods; and (iv) that the probability of seed removal by Formica rufibarbis (the only ant species present in the study area) varies over the season, peaking in early July. In conclusion, our results show that despite differences in seed size, plants with ant-dispersed seeds show highly synchronous flowering, suggesting that strict myrmecochores in our study area may have adapted their phenologies to the seasonal availability of dispersers.
\end{abstract}

Keywords: elaiosome, flowering phenology, fruiting phenology, seed removal, seed size, myrmecochory.

\section{Introduction}

The study of interactions between plants and animals has attracted increasing attention in recent decades, and is currently a key aspect in the evolutionary ecology of plants (Herrera \& Pellmyr 2002). Plant-animal interactions include mutualist interactions such as pollination, active defense and seed dispersal. Within this latter category, seed dispersal by ants has been frequently studied, but many aspects of its ecological and evolutionary significance remain unclear (for reviews see Beattie \& Hughes 2002; Gorb \& Gorb 2003; Giladi 2006).

The general pattern of this type of dispersal is as follows: (i) myrmecochores produce seeds bearing an energy-rich elaiosome; (ii) ants collect these seeds and transport them to their nest; and (iii) in the nest the ants consume the elaiosomes and discard the intact seed

Correspondence: Javier Guitián

Email: bvjguiti@usc.es outside the nest where it may germinate. In addition to the presence of an elaiosome, specialized myrmecochorous plants may also show other diverse morphological, anatomical, biochemical and/or phenological characteristics associated with myrmecochory. A number of plants are also considered to be 'unspecialized myrmecochores', in that ant dispersal occurs in the absence of an elaiosome (see Gorb \& Gorb 2003).

Phenological characteristics associated with myrmecochory are of particular interest. Turnbull and Culver (1983) and Hughes and Westoby (1990) found that rates of seed removal by ants varied throughout the year. Thompson (1981) found that specialized myrmecochorous species typically showed different phenologies to species with seeds dispersed by other mechanisms. Both Handel and Beattie (1990) and Oberrath and BohningGaese (2002) found that these species typically flower early in season, and suggested that this is an adaptation for myrmecochory. Specifically, three ant-related explanations have been proposed for the widely observed earlier 
flowering of myrmecochorous species: (i) that ant activity in temperate regions typically peaks in spring and declines in summer; (ii) that the availability of alternative food for ants (basically insect corpses) typically peaks in summer, so that seeds produced early are subject to less competition; and (iii) that when there is temporal partitioning in the activity of seed dispersers and seed predators, the timing of seed release may be under selection to coincide with the peak activity of high-quality dispersers (Giladi 2006). All three explanations imply a faster rate of removal of seeds before the start of summer and, thus, the existence of selective pressures that may favor particular flowering phenologies.

However, a number of alternative hypotheses have been proposed (see Turnbull \& Culver 1983; Oberrath \& Bohning-Gaese 2002). First, the 'pollination hypothesis' suggests that these species tend to flower early not to favor seed dispersal by ants, but rather to favor pollination by insects active early in the year. Second, the 'phylogenetic hypothesis' suggests that the typically early flowering of myrmecochorous plants reflects pre-existing adaptations in those groups in which myrmecochory has developed. Third, the 'seed-size hypothesis' suggests that myrmecochorous plants typically produce small seeds, and that small seeds are typically produced earlier in the year than larger seeds simply because they take less time to manufacture. Fourth, the 'habitat hypothesis' suggests that most temperate-region myrmecochorous plants are woodland species, which typically show earlier flowering than species from other habitats.

In the present study, we aimed to assess whether the early flowering/fruiting of myrmecochorous species can be considered to be the result of adaptation to ant dispersal. To this end, we studied the flowering and fruiting phenology of the common herb and shrub-layer species of a deciduous woodland over a 1-year period, and simultaneously analyzed ant activity patterns, the availability of alternative foods for ants, and the rate of removal of seeds by ants. This is a novel design in three main respects. First, we included only specialized myrmecochores (i.e. myrmecochores with elaisosomes) in our definition of 'myrmecochore'. Second, we considered a single plant community, beech woodland (Fagus sylvatica), thus avoiding possible variation because of differences in habitat. Third, only one ant species (Formica rufibarbis) is present in the study area, thus, the potential for efficient selection is likely to be more consistent than in an area with several ant species (see Herrera 1989).

\section{Materials and methods}

\section{Study area}

The study was carried out in 2003 in a deciduous woodland located in the Sierra del Caurel, at the western end of the Cantabrian Range in north-west Spain, close to the village of Busmayor (Barxas, León, 42 $37^{\prime} 21^{\prime \prime} \mathrm{N}$, $07^{\circ} 01^{\prime} 42^{\prime \prime} \mathrm{W} ; 1200 \mathrm{~m}$ a.s.1.). This woodland has a total area of 17 ha and is dominated by beech (Fagus sylvatica), together with holly (Ilex aquifolium), rowan (Sorbus aucuparia) and birch (Betula celtiberica), and small patches of oakwood (Quercus pyrenaica) at the woodland fringe. The herb/shrub layer comprises 31 common species, all of which were monitored in the present study (Appendix I). The 31 species belong to a total of 15 families, including Ranunculaceae with 5 species, and 9 families with only a single species.

\section{Flowering and fruiting phenology}

Phenology was monitored from the beginning of March (when flowering starts in this area) to the end of September (when fruiting finishes). Over this period we visited the woodland every 2 weeks and recorded which species bore flowers and which species bore mature fruit on each visit. At each visit we walked a transect through the woodland, evaluating between 15 and 20 individuals of each species. We considered the flowering period of each species to be the period between the start of flowering of the first individual and the end of flowering of the last individual, and the fruiting period to be the period between the beginning and the end of the seed-release period. Seed release is highly synchronic within each species (J. Guitián and J. L. Garrido, pers. obs., 2003), so we can assume that, for each plant species, the moment of peak seed availability on the ground corresponds to the moment of peak fruit number on plants.

For seed characterization, we collected seeds from all species and recorded the presence/absence of elaiosome; $11(35.4 \%)$ of the 31 species had seeds with elaiosome. For 22 of the 31 species we determined the dry weight of 50-100 seeds, and calculated the mean seed weight, which ranged from $0.34 \pm 0.13 \mathrm{mg}$ in Daphne laureola to $10.90 \pm 0.83 \mathrm{mg}$ in Helleborus foetidus; for the remaining nine species, we were unable to collect sufficient seeds for reliable determination of mean seed weight.

\section{Ant activity and availability of alternative food}

Ant activity and the availability of alternative ant food were estimated every 4 weeks by random sampling of insects and other arthropods using pitfall traps consisting of a glass set into the soil at ground level containing water plus a surfactant. For each sample, the trap was left in place for $48 \mathrm{~h}$, always on days without rain. Trapped insects were stored in $70 \%$ ethanol until laboratory identification by specialists. A total of 18 traps were systematically placed at 20-m intervals on the woodland floor. The positions of the traps were varied slightly for each sample 
between sampling periods. Ant activity in each month was indicated by the total number of individuals of Formica rufibarbis captured in that month's sample (total $n=870$ individuals, all of F. rufibarbis). Likewise, the availability of alternative food was indicated by the total number of individuals of all non-ant arthropod species captured in that month's sample (it is important to note that this is an approximation only because the peak in trapped numbers presumably corresponds to the activity peak, which can be expected to precede the peak in availability as food, i.e. as corpses). In July, a minor mishap meant that we did not obtain a full insect sample, but we are confident that at least 200 ants were trapped in this month.

\section{Seed removal}

For seed removal experiments, we selected two plant species with abundant seed production as models, Erythronium dens-canis and Helleborus foetidus. Erythronium dens-canis is an early flowering species, chosen to allow us to monitor seed-removal activity by ants in the early part of the community fruiting period. At fortnightly intervals, at approximately $9.00 \mathrm{AM}$, we placed 10 seeds of each species in five randomly located squares $(0.25 \mathrm{~m} \times 0.25 \mathrm{~m}$, henceforth referred to as 'blocks'; i.e. 50 seeds per experiment). Seed removal from the different blocks was recorded after $30 \mathrm{~min}$. We assumed that all seeds lost from the blocks were removed by ants because other important seed predators in the study area (notably rodents) have nocturnal-crepuscular activity patterns. Fresh seeds were not available throughout all of the study period, so we used frozen seeds of these species. We previously verified that frozen seeds, after $4 \mathrm{~h}$ thawing at ambient temperature, are removed at the same rate as fresh seeds. The removal experiments were terminated when seeds were no longer removed (i.e. when ant activity became negligible, at the end of August); thus, the experiments were carried out for a total of 6 days ( $E$. denscanis) and 4 days (H. foetidus). Prior to the date on which the seed removal experiments were carried out (1 July), no elaiosome-bearing seeds were available in the study area.

\section{Data analysis}

Comparison of phenological patterns For the comparison of phenological patterns between elaiosome-bearing and non-elaiosome-bearing species we used the non-parametric method described by Estabrook et al. (1982). This method was initially developed to compare phenological patterns between two populations of plants: for example, the researcher considers all flower buds on 10 plants in population A and 10 plants in population B; on a series of dates over the flowering season, he/she records the cumulative numbers of population-A buds and of population-B buds that have opened to date, and expresses each number as a proportion of the total number of buds that have opened on the 10 plants in that population by the last day of monitoring; then, considering the date on which the differences between the two proportions (D) is maximal $\left(D_{\max }\right)$, the analysis assesses whether $D_{\max }$ exceeds a critical value indicative of a statistically significant difference between the two proportions and, thus, between the two phenological patterns. The critical value for $P=0.05$ is given by $1.36 \times[(m+n) /(m \times n)]^{1 / 2}$, where $m$ is the total number of flower buds eventually opening in population $\mathrm{A}$ and $\mathrm{n}$ is the total number of flower buds eventually opening in population B (see Estabrook et al. 1982). In the present study, we applied this method to species instead of individual buds, and to two groups of species (with elaisome or without elaiosome) instead of two populations of single species. In other words, we used the method to assess whether the maximal difference between the proportion of strict myrmecochore species in flower and the proportion of non-myrmecochores in flower was indicative of a significant difference in flowering phenology between the two groups. Likewise, we used this method to compare fruiting phenologies. To compare synchrony between the fruiting peak and the ant activity peak, we used Kendall's coefficient of concordance.

Presence of elaiosome and seed weight To assess whether seed weight differs significantly between species with or without elaiosome, we considered a total of 1383 seeds from a total of 22 species (for the remaining species we were unable to collect sufficient seeds for reliable statistical analysis). An analysis was carried out with the weight of each individual seed as the dependent variable and the presence/absence of elaiosome as a fixed-effect factor. As individual seeds were not independent samples, but rather grouped within species, species was additionally included in the analysis as a random-effect factor. The factor species was additionally nested within the factor presence/absence of elaiosome, to assess whether species had a significant effect considering only species with elaiosome-bearing seeds and/or considering only species with non-elaiosome-bearing seeds. These analyses were carried out with a mixed linear model using the Mixed procedure in the statistics package SAS (SAS Institute 1999).

Seed removal Data from the seed removal experiments were analyzed using a generalized mixed model assuming a binomial distribution of the probability that a seed would be removed from a given block on a given day. The analysis was carried out using the GLIMMIX procedure 
of the statistics package SAS (SAS Institute 1999). The date of each experiment was included in the model as a fixedeffect factor. To account for possible effects of spatial variation among blocks, we additionally included block as a random-effect factor.

\section{Results}

\section{Fruiting and flowering phenology}

Considering all 31 species together, the flowering period began at the beginning of March and ended in mid September, with the peak (i.e. peak number of species) in mid June; the fruiting period (i.e. the period of seed availability) began in mid June and ended in late September, with the peak in mid July (Fig. 1).

Flowering of the 11 species with elaiosome-bearing seeds began in mid March, peaked in mid May, and continued until mid July. Flowering of the 20 species with non-elaiosome-bearing seeds likewise began in mid March, peaked in mid June, and continued until mid September. These data indicate that most species with elaiosome-bearing seeds flower approximately 4 weeks earlier than most species with non-elaiosome-bearing seeds. Despite this difference in flowering phenology, fruiting phenologies of the two groups of species were very

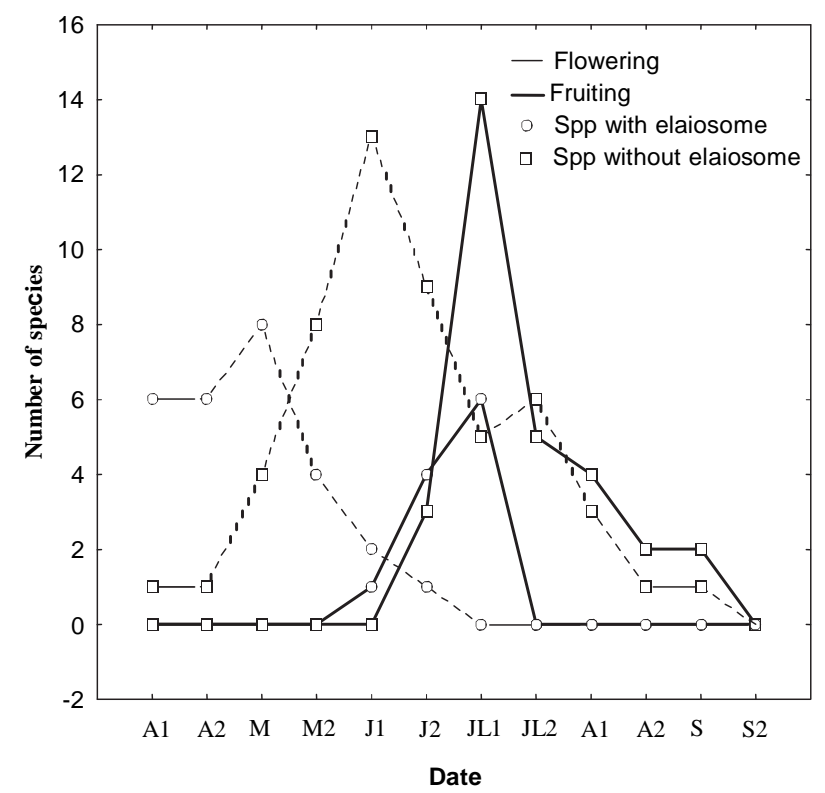

Fig. 1 Flowering and fruiting phenology of species producing seeds with and without elaiosome. Each point shows the number of species bearing flowers/fruits on that date. The number of elaiosome-producing species in flower peaked approximately 1 month earlier than the number of non-elaiosome-producing species in flower; by contrast, the number of elaiosomeproducing species with fruit peaked around the same time as the number of non-elaiosome-producing species with fruit. similar (Fig. 1). Comparison of the phenological patterns confirmed that the flowering phenology of species with elaiosome-bearing seeds differed significantly from that of species with non-elaiosome-bearing seeds $\left(D_{\max }=0.75\right.$, above the critical value of 0.611 for $P<0.05)$. By contrast, the fruiting phenology did not differ significantly between the two groups $\left(D_{\max }=0.45\right.$, below the critical value of 0.660 for $P<0.05)$.

\section{Ant activity and availability of alternative food}

In total we captured 1492 arthropod specimens, of which $58.3 \%$ were ants and $31.5 \%$ were beetles; other groups were present in smaller numbers (dipterans $5.2 \%$; myriapods $1.1 \%$; arachnids $0.8 \%$; thysanopterans $0.2 \%$; others $2.9 \%$ ). Ant activity in the study area commenced at the end of April, peaked at the end of June, and continued until September (Fig. 2). Calculation of Kendall's coefficient of concordance $(P<0.001)$ indicated a significant association between the fruiting peak and the ant activity peak. Other arthropod groups (i.e. alternative food for ants) were present throughout the summer, with a late increase in September (Fig. 2), and thus arthropod corpses can be assumed not to have competed significantly with seeds as a food resource for ants at the moment of seed release.

\section{Seed weight and seed removal}

Seeds with elaiosomes weighed significantly more than seeds without elaiosomes $(5.47 \pm 3.36 \mathrm{mg}$ vs $1.99 \pm 1.45 \mathrm{mg}$, respectively; $\left.F_{11,20}=11.57, P=0.003\right)$. Seed weight also varied significantly among species after controlling for the effect of elaiosome $(Z=3.15, P=0.0008)$.

The rate of removal of frozen seeds did not differ from that of fresh seeds $\left(X^{2}=1.5000, P=0.2207\right)$. For both seeds

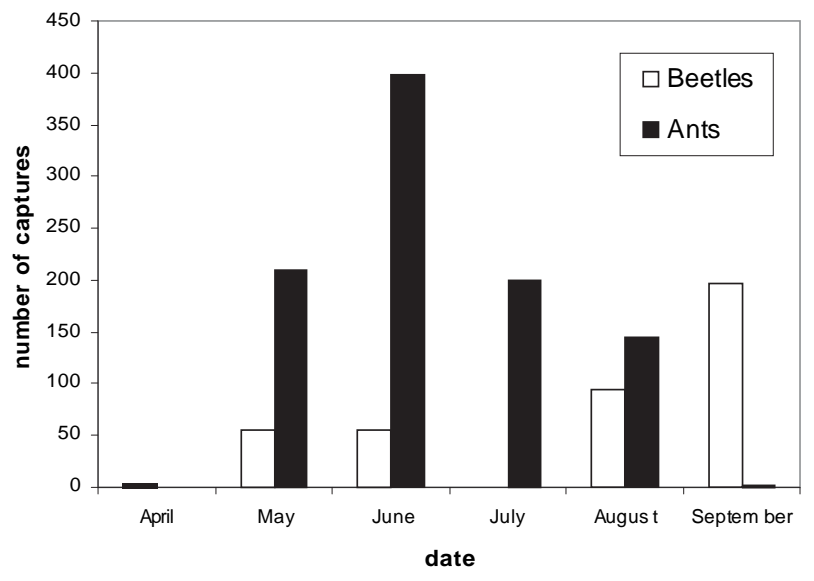

Fig. 2 Variation in the number of captures of ants and beetles in each monthly sample. 
of H. foetidus and seeds of E. dens-canis, the probability of seed removal varied significantly over the season (H. foetidus $\quad F_{5,19.8}=4.38, \quad P=0.0075 ; \quad$ E. dens-canis $F_{3,1.6}=7.79, \quad P=0.0041$ ), with the probability of seed removal declining gradually and falling to zero on the last 2 days of the experiment (Fig. 3). The probability of seed removal peaked in the second half of June, coinciding with the observed peak in ant activity.

\section{Discussion}

Is myrmecochore phenology an adaptation for ant dispersal?

This study was carried out in a beechwood community in a montane area of the Iberian Peninsula with Mediterranean bioclimate, in which plant breeding is restricted to a relatively short period between the cold winter and the summer drought. Our findings should be interpreted bearing in mind this ecological context.

Our results show that the flowering periods of specialized myrmecochorous plants occur markedly earlier in the season than those of non-myrmecochores, but that the two groups do not differ in the timing of the fruiting period. This result contrasts with that obtained by Oberrath and Bohning-Gaese (2002), who found that both the flowering and the fruiting of ant-dispersed

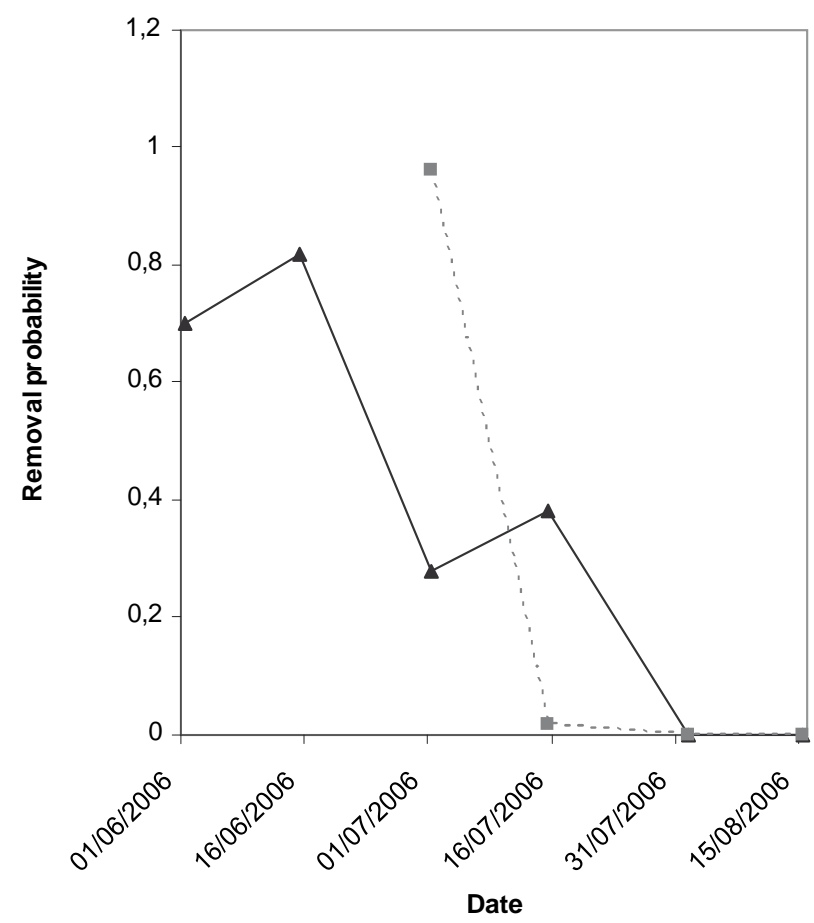

Fig. 3 Time-courses of probability of seed removal by ants over the study period. Seed removal experiments were carried out with seeds of Helleborus foetidus ( $\cdots)$ and Erythronium dens-canis'(-). species occurred earlier in the season than in nonmyrmecochores; however, both in our study and the study of Oberrath and Bohning-Gaese (2002), the fruiting of myrmecochores coincided with the ant activity peak. In addition, in the present study the fruiting period of myrmecochores preceded the period of peak availability of alternative food for ants (Hulme 1992). In a similar study, Ohkawara et al. (1997) found that seeds of Coryalis ambigua are efficiently dispersed by ants within a short period of time, generally before the arrival of seed-predatory beetles. Our results also indicate that specialized myrmecochores (i.e. species with elaiosome-bearing seeds) have heavier seeds and longer fruiting periods than other species. Various authors have pointed out that, while the elaiosome typically accounts for only approximately $6 \%$ of total seed weight, it represents approximately $30-35 \%$ of the seed's total energy cost (Lisci et al. 1996); thus, it is reasonable to suppose that elaiosome-bearing seeds may require a longer development time.

Our results also show that the probability of seed removal by ants depends on the date on which they are released: removal rates were highest during the period of peak ant activity and declined dramatically at the start of the summer drought. Temporal variations in rates of seed removal by ants have been reported in previous studies and have been attributed to different causes (see Hughes \& Westoby 1990). In the present study, we found that elaiosome-bearing seeds released after the end of July are very unlikely to be dispersed, at least in the two species tested.

\section{Evolutionary consequences}

The climatic conditions existing on the southern side of the Cantabrian Range place strong constraints on the activity of plants and their dispersers, in view of the harsh winter and summer drought. In the case of plants and ant dispersers, the period available for plant fruiting/ flowering and for completion of the annual nest cycle is only approximately 5 months. Given this scenario, June and July are the key periods: ants show peak activity, alternative food resources for ants are still scarce and, thus, the probability of ant dispersal of elaiosome-bearing seeds is maximal. Plants with elaiosome-bearing seeds are presumably obliged to flower early in order to release their seeds during the ant activity peak, bearing in mind that these seeds are typically heavier and can be expected to have a longer development time than non-elaiosomebearing seeds. In line with this, our experiments indicate that seed removal by ants after the end of July is negligible.

Turnbull and Culver (1983) showed that the release of seed of a myrmecochore is even more finely tuned to the 
activity pattern of a particular ant species, and Retana and Cerdá (2000) found that increases in plant cover are typically associated with reductions in ant species diversity. In line with this, the beechwood considered in the present study has a dominant species of ant, Formica rufibarbis. In a recent study, Manzaneda (2005) reported that various plant communities in our study area have few species of seed-dispersing ants. In such communities, selective pressures on the phenology of myrmecochorous plants can be expected to be more consistent in time and, thus, more efficient than in more diverse communities, in which we can expect greater variation in the magnitude and intensity, and indeed direction, of selective pressures (see Herrera 1989).

In conclusion, our results show that despite the heterogeneous characteristics of the myrmecochorous plants considered in the present study (in terms of taxonomic family, seed size, pollination mechanisms), practically all of these species showed early flowering and highly synchronous fruit production. This suggests that strict myrmecochores in our study area may have adapted their phenologies to the seasonal availability of dispersers. Thus, seed dispersal by animals can have substantial consequences for the phenology, reproduction and fitness of plants.

\section{Acknowledgments}

The authors thank Pablo Guitián, Carlos Teira, Guy Norman and Asier R. Larrinaga for providing useful comments and for field assistance, and Antonio Manzaneda (Estación Biológica de Doñana), Alberto Tinault (Universidad de Granada) and Carlos Otero (Universidad de Santiago) for insect identification. This study was supported by grant BOS2003-03979-C02-01 (Ministerio de Ciencia y Tecnología) and the Fundación RAMON ARECES.

\section{References}

Beattie A. J. \& Hughes L. (2002) Ant-plant interactions. In: Herrera C. M. \& Pellmyr O. (eds). Plant-Animal Interactions. Blackwell Publishing Ltd, London, pp. 211-235.
Estabrook G. F., Winsor J. A., Stephenson A. G. \& Howe H. F. (1982) When are two phenological patterns different? Botanical Gazette 143: 374-378.

Giladi I. (2006) Choosing benefits or partners: a review of the evidence for the evolution of myrmecochory. Oikos 112: 481492.

Gorb E. \& Gorb S. (2003) Seed Dispersal by Ants in a Deciduous Forest Ecosystem. Mechanism, Strategies, Adaptations. Kluwer Academic Publishers, Dordrecht.

Handel S. N. \& Beattie A. J. (1990) Seed dispersal by ants. Scientific American 263: 58-76.

Herrera C. M. (1989) Pollinator abundance, morphology, and flower visitation rate: analysis of the 'quantity' component in a plant-pollinator system. Oecologia 80: 241-248.

Herrera C. M. \& Pellmyr O. (eds) (2002) Plant-Animal Interactions. An Evolutionary Approach. Blackwell Science, Oxford.

Hughes L. \& Westoby M. (1990) Removal rates of seeds adapted for dispersal by ants. Ecology 71: 138-148.

Hulme P. E. (1992) The ecology of a temperate plant in a Mediterranean environment: post-dispersal seed predation of Daphne laureola. In: Thanos C. A. (ed.). Plant-Animal Interactions in Mediterranean-Type Ecosystems. Proceedings of the 6th International Conference on Mediterranean Climate Ecosystems. University of Athens, Athens, pp. 198-204.

Lisci M., Bianchini M. \& Pacini E. (1996) Structure and function of the elaiosome in some angiosperm species. Flora 191: 131141.

Manzaneda A. J. (2005) Ecología y evolución de la dispersión de semillas de Helleborus foetidus (Ranunculaceae). Variación geográfica en las interacciones planta-animal (Doctoral Thesis). University of Sevilla, Spain.

Oberrath R. \& Bohning-Gaese K. (2002) Phenological adaptation of ant-dispersed plants to seasonal variation in ant activity. Ecology 83: 1412-1420.

Ohkawara K., Ohara M. \& Higashi S. (1997) The evolution of ant-dispersal in a spring-ephemeral Corydalis ambigua (Papaveraceae): timing of seed-fall and effects of ants and ground beetles. Ecography 20: 217-223.

Retana X. \& Cerdá X. (2000) Patterns of diversity and composition of Mediterranean ground ant communities tracking spatial and temporal variability in thermal environment. Oecologia 123: 436-444.

SAS Institute (1999) SAS/STAT Software. SAS Institute, Cary.

Thompson J. N. (1981) Elaiosomes and fleshy fruits: phenology and selection pressures for ant dispersed seed. American Naturalist 117: 104-108.

Turnbull C. L. \& Culver D. C. (1983) The timing of seed dispersal in Viola nuttallii: attraction of dispersers and avoidance of predators. Oecologia 59: 360-365. 


\section{Appendix I}

Plant species examined, presence/absence of elaiosome and mean seed mass

\begin{tabular}{|c|c|c|c|c|c|c|c|}
\hline Species & Elaiosome & $n$ & Seed mass (mg) & Species & Elaiosome & $n$ & Seed mass (mg) \\
\hline Aconitum lycoctonum & NE & 0.60 & 3.90 & Lapsana communis & NE & 0.70 & 0.44 \\
\hline Ajuga reptans & NE & & & Meconopsis cambrica & NE & 0.60 & 0.31 \\
\hline Allium ursinum & WE & 0.80 & 5.48 & Melittis melissophyllum & NE & & \\
\hline Anemone nemorosa & WE & & & Mercurialis perennis & WE & 0.61 & 5.38 \\
\hline Aquilegia vulgaris & $\mathrm{NE}$ & 0.37 & 1.53 & Narcissus asturiensis & WE & & \\
\hline Asperula odorata & NE & 0.44 & 0.91 & Omphalodes nitida & NE & 0.24 & 2.20 \\
\hline Chaerophyllum hirsutum & NE & 0.83 & 3.42 & Oxalis acetosella & NE & & \\
\hline Corydalis cava & WE & 0.60 & 1.74 & Primula vulgaris & WE & 0.80 & 1.16 \\
\hline Corydalis claviculata & NE & & & Ranunculus platanifolius & NE & 0.79 & 2.25 \\
\hline Daphne laureola & NE & 0.100 & 0.35 & Rubus sp. & NE & & \\
\hline Erythronium dens-canis & WE & 0.39 & 6.83 & Sanicula europea & NE & 0.70 & 5.24 \\
\hline Euphorbia amygdaloides & WE & 0.60 & 3.48 & Saxifraga spathularis & NE & & \\
\hline Euphorbia hyberna & WE & 0.85 & 8.78 & Stellaria holostea & NE & 0.53 & 2.85 \\
\hline Geranium robertianum & NE & 0.94 & 1.81 & Valeriana pyrenaica & NE & 0.60 & 1.00 \\
\hline Helleborus foetidus & WE & 0.25 & 10.91 & Viola riviniana & WE & & \\
\hline Hyacinthoides non-scripta & NE & 0.59 & 1.69 & & & & \\
\hline
\end{tabular}

WE, seeds found to bear elaiosome; NE, seeds found not to bear elaiosome; $n$, number of seeds collected for estimation of mean seed mass. 